This item was submitted to Loughborough's Research Repository by the author.

Items in Figshare are protected by copyright, with all rights reserved, unless otherwise indicated.

\title{
Managing and normalising emotions and behaviour: a conversation analytic study of ADHD coaching
}

PLEASE CITE THE PUBLISHED VERSION

http://dx.doi.org/10.1057/9781137428318_26

PUBLISHER

(C) Palgrave Macmillan

VERSION

AM (Accepted Manuscript)

\section{PUBLISHER STATEMENT}

This work is made available according to the conditions of the Creative Commons Attribution-NonCommercialNoDerivatives 4.0 International (CC BY-NC-ND 4.0) licence. Full details of this licence are available at: https://creativecommons.org/licenses/by-nc-nd/4.0/

\section{LICENCE}

CC BY-NC-ND 4.0

\section{REPOSITORY RECORD}

Bradley, Louise, and Carly W. Butler. 2019. "Managing and Normalising Emotions and Behaviour: A Conversation Analytic Study of ADHD Coaching". figshare. https://hdl.handle.net/2134/18407. 
To appear in Palgrave Handbook of Child Mental Health

MANAGING EMOTIONS AND NORMALISING ADHD

Louise Bradley (Loughborough University, UK)

Carly W. Butler (Loughborough University, UK)

\section{Chapter Contents}

1. Introduction

2. Project overview

3. Co-producing emotional knowledge as ordinary

4. Normalising anger

5. Using metaphors to construct experiential aspects of anger

6. Self-talk thinking tool

7. Summary

8. Clinical relevance

9. Clinical practice highlights

10. References

11. Recommended reading

\section{Introduction}

Attention Deficit Hyperactivity Disorder (ADHD) is the most commonly diagnosed disorder in childhood with worldwide prevalence estimated around 5 per cent (Polanczyk et al, 2007). Those that are given a diagnosis of ADHD often present with emotional and social difficulties including poor emotional regulation and a greater excessive emotional expression, especially for anger and aggression (Wehmeier, Schacht, \& Barkley, 2010). Such difficulties impact self-esteem and self-concept, although this impact has rarely been addressed in research (Ryan \& McDougall, 2009; Wehmeier, Schacht, \& Barkley, 2010). Instead, research has focused on assessment, diagnosis, and treatment (Barkley, 2006), or behaviour 
management for parents or carers to reduce and manage undesirable behaviour (Gavita \& Joyce, 2008).

Discussions around ADHD are contentious and there has been much debate about its origin and validity that has divided professional and public opinion. The research behind this chapter does not set out to enter into this debate, but instead seeks to consider the emotional and social problems experienced by children that have largely been ignored. The focus for the research project then is about the everyday lives and experiences of children who live with a diagnosis of ADHD, and to understand more about the way they understand and define themselves, their emotions and behaviours, and descriptions of ADHD.

This chapter will look at the practices used to help children understand, share, and co-produce their knowledge of emotions during a cognitive-behavioural program for children with a diagnosis of ADHD. Drawing on the ideas of Edwards and Mercer (1987), the concern will be about how 'common knowledge' becomes constructed, developed, and displayed in talk. As such the chapter will examined how 'knowledge is actually built and shared' (Edwards \& Mercer, 1987, p.156) within the interactions and to what ends. The analysis will show how shared knowledge and understanding of emotions are collaboratively constructed through a series of step-by-step questions and discussions aimed at helping children recognize emotions in themselves and others, for the purpose of assisting them to manage and control their emotions in the future.

The chapter will also draw on Harvey Sacks' work on 'doing being ordinary' which he suggests is done by 'spend[ing] your time in usual ways, having usual thoughts, usual interests...' (Sacks, 1984, p. 415). Sacks' idea is that people use 'ordinariness' as a rhetorical 
alternative to 'extraordinariness', to normalize events and counter any negative inferences that could otherwise be made (see also Burridge, 2008; Lawrence, 1996; Sneijder \& te Molder, 2009). Within this chapter, we show how questions, descriptions, and collective person references are used to normalise emotions and counter any negative inferences that could be made about children and ADHD. The chapter will also consider the ways in which emotional knowledge is built, shared, and co-produced to claim 'ordinariness' as a device to 'unpathologise' emotion and offer children an alternative identity to the 'disordered'

construct that is so often bound to ADHD (see Bradley \& Butler, (forthcoming); Brady, 2014; Danforth \& Navarro, 2001; Horton-Salway, 2011). The effects of a disordered identity on a child's social, emotional and behavioural well-being have been reported (see Houck et al., 2011; Krueger \& Kendall, 2001), but we know very little about the interactional practices that can help support, protect or enhance a child's well-being. The specific interactional practices identified and discussed in this chapter will have practical implications for those working with vulnerable children.

\section{Project overview}

The research project from which this chapter derives was interested in identifying the supportive practices used by professionals to help children with emotional, social, and behavioural difficulties construct a more positive sense of self. Data for the project was collected from two settings, one of which was a charity organization that supports families, children, and adults with ADHD through regularly run support groups and training programs. One such program is 'RAPID', a cognitive-behavioural psychoeducational program aimed at helping children achieve future goals by helping them improve their ability to pay attention, reduce impulsive behaviours, problem-solve, and develop social skills (Young, 2009; 2013). 
Over the course of a nine-week program the sessions were video-recorded and then analysed to identify supportive practices that help children enhance their behaviour, and social and emotional well-being. As such, the program was a rich site for the supportive practices that were the focus of the project, and of particular interest here was the way in which the children's knowledge and skills were built week by week. A specialist ADHD coach delivered the RAPID program using a manual based on standard cognitive-behavioural tools and techniques, to provide direct intervention to teach children cognitive, social and emotional skills, and moral values (Young, 2013). The delivery involved teaching, coaching, and reinforcing positive behaviours through a range of cognitive tools, which formed a real life 'toolbox' that the children could draw on to help manage their thoughts, emotions, and behaviours.

What is often missing from programs such as RAPID, and in research that develops and assesses them, is a focus on the interactional practices through which the concepts and tools are delivered. As such, we demonstrate how the co-production of emotion knowledge and the ordinariness of emotional states underpin the practical delivery of the tools in the RAPID program, and how these aspects are presented through the micro-detail of talk-in-interaction. We begin by showing how emotional knowledge is co-produced as ordinary, and then show how these fundamental aspects of emotional management are drawn on in demonstrating the tools to the children. In so doing, our analysis demonstrates clinical relevance by bridging the gap between theory and practice, as delivery of the program will be examined as a practical concern. This interactional approach identifies the practices being used by the coach to deliver the program. Discussion of these practices will be valuable for practitioners as 
research often treats such methods as implicitly, common-sensibly, or intuitively known by those delivering intervention.

\section{Co-producing emotional knowledge as ordinary}

Throughout the nine-week program, developing emotional knowledge was an on-going concern, based on the understanding that if children can recognise their own as well as others' emotions, they can learn to control and adapt their behaviour. The following extract is from a session designed to help the children develop their problem-solving skills, which has involved discussing how paying attention to the emotional states of others can help them 'spot and recognise problems' to 'avoid getting told off'. Here the focus is on 'listening' as a tool for emotion recognition. Our focus is on how understandings about emotional displays are co-produced between the coach and the children. Standard Jeffersonian conventions are used for the transcription, see page $\mathrm{X}$ for a description of the symbols used.

(1)

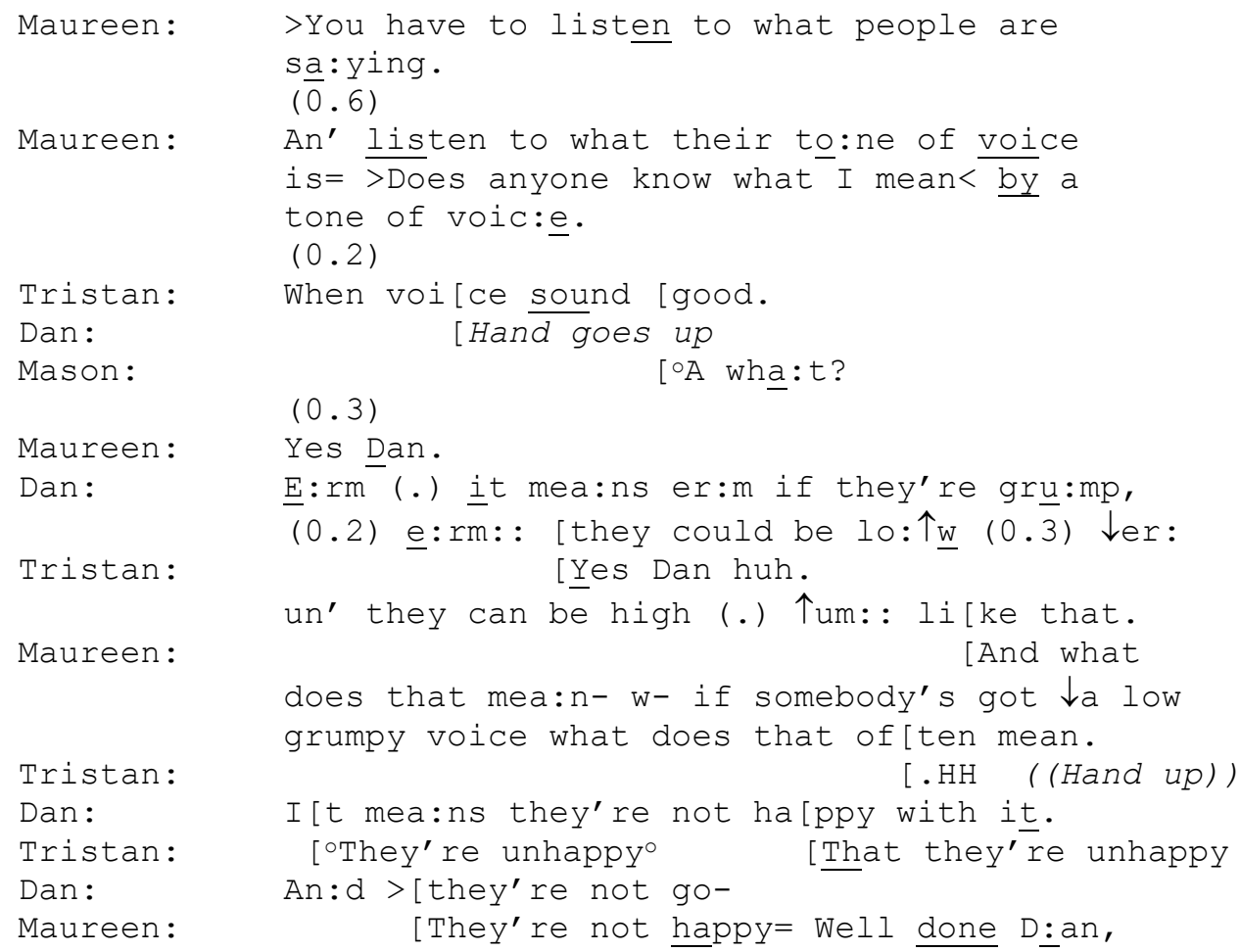


Maureen introduces the need to listen to people's 'tone of voice' (line 4-5) but does not assume any shared knowledge as she initiates an understanding check, 'does anyone know what I mean by a tone of voice' (line 5-6). The question starts off an Initiation-ResponseEvaluation (IRE) sequence (Mehan, 1979), a classic pedagogic tool, which invites displays of existing knowledge to generate a shared understanding. Dan is selected to answer and offers, 'Erm it means erm if they're grump, (0.2) erm they could be low (0.3) $\downarrow$ er: un' they can be high (.) 个um like that' (lines 13-16), to demonstrate his understanding of different tones of voice that he embodies through his prosodic production. He also reveals that he knows someone's tone of voice can indicate mood, which occasions Maureen's question, 'And what

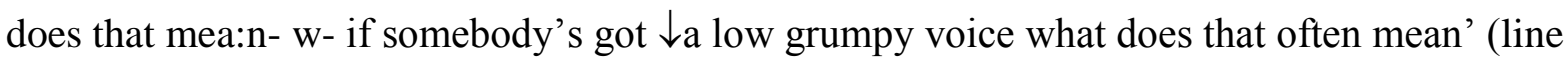
17-19), uttered using the same words (low and grumpy) and prosodic embodiment as Dan. The question invites Dan to elaborate, 'It mea:ns they're not happy with it' (line 21), to show he understands the relationship between tone of voice and emotional states. Maureen issues an 'affiliative repeat' (Margutti \& Drew, 2014, p. 7) and positive assessment, 'They're not happy. 'Well done D:an,' (lines 24) to evaluate and close the sequence. The IRE has been used to elicit a display of recognition about tone of voice and how talk can indicate emotional states.

A second feature of the extract is the work accomplished by Maureen and Dan's use of unmarked person references: 'people' (line 1), 'their' (line 4), 'they're' (lines 13, 21, 22, 23, 24), 'they' (lines 14, 16), and 'somebody's' (line 18). These collective and non-specific references provide the speaker a useful ambiguity to talk about what people do in general (Sacks, 1984). For Maureen and Dan the ambiguity of collective references has allowed them to speak about the indefinite 'everyone' without excluding themselves, in a way that suggests 
there is nothing extraordinary about using tone of voice to indicate that someone is 'happy' or 'unhappy'. Topicalising their tacit understanding in this way introduces tone of voice as an ordinary practice that people use to display and recognise others' emotional states, and as such tone of voice is made available for the children to use. This ordinary tool can be used by the children for future problem-solving to help them spot and recognise 'problems' based on other people's emotions in relation to their own behaviour or actions. This theme continues throughout the analysis; the tools introduced throughout the program are offered as practical methods for the children to use to manage ordinary everyday problems.

The IRE sequence and usefully inclusive and ambiguous person references are used to construct emotional knowledge and behaviour as shared and ordinary. However, the basis for these sessions taking place is that the children's behaviour in reaction to their emotions is often extraordinary - hence the diagnosis of ADHD - and that Maureen, as coach, has expert knowledge on managing emotions. A key aspect of the work then is that both Maureen's authority and the extraordinary behaviour of the children is minimised throughout. The next extract begins to identify the boundaries of ordinary emotions using similar practices to those already identified (questions, descriptions, and collective person references) building a common knowledge of 'strong feelings' to first construct an ordinary alternative, and second to introduce the need for control.

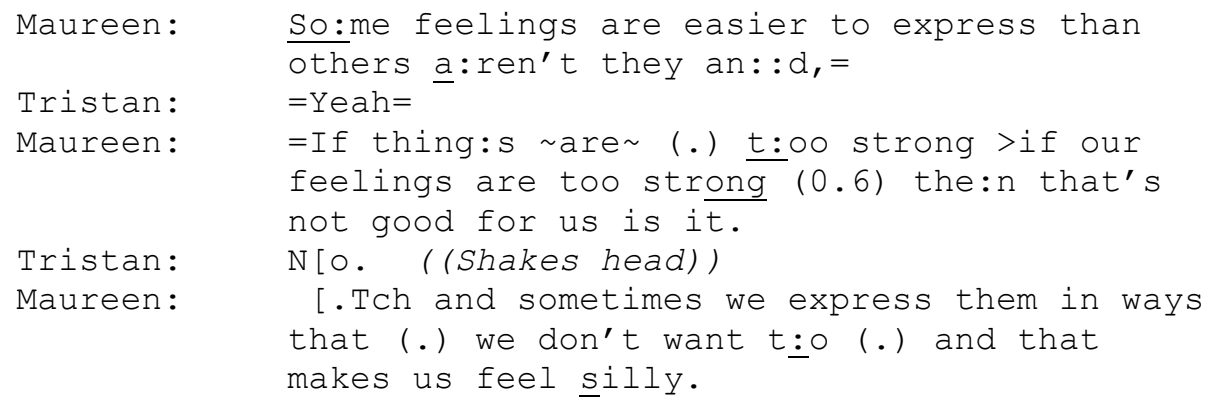




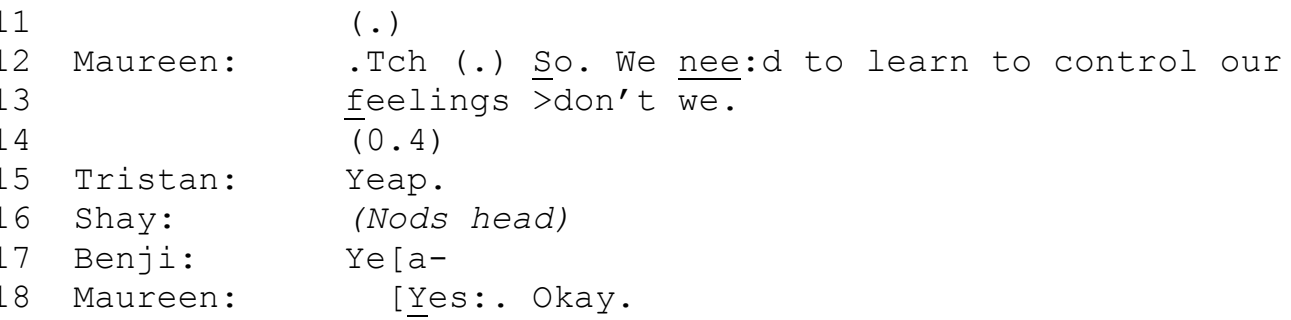

Maureen's opening turn, 'So:me feelings are easier to express than others $\underline{a}: r e n ’ t$ they', is a declarative + tag question. While Tristan confirms this (line 3), the tag is not designed to elicit a response from the children as Maureen's elongated 'an::d' allows her to hold open her turn by projecting more to come (Schegloff, 2007). The mid-turn tag treats the statement 'some feelings are easier to express than others' as already known by the children (see Hepburn \& Potter, 2011) and draws attention to this as part of the knowledge building process. The dialogic format is preserved within a 'monologic' turn that allows for (as in this case), but does not require, responses by the children. The upshot of this is that the children are constructed as 'knowing', and as sharing access to the experience of emotional expression.

Maureen completes her turn with 'if thing:s $\sim$ are (.) t:oo strong >if our feelings are too strong (0.6) the:n that's not good for us is it' (lines 4-6). This starts to establish boundaries of normal emotion, with some feelings being 'too strong' and 'not good'. However, these 'strong feelings' are still produced as ordinary via Maureen's use of the possessive pronoun 'our' and collective pronoun 'us' to speak on behalf of her, Lucy, the children, and all possible members, as in extract 1 . The ambiguity manages the notion that it is not just the children who have feelings that are 'too strong' and 'not good'; the children are not being singled out as anything other than 'ordinary', normalising any potential inferences that could be made about children and ADHD (Sacks, 1984). 
The ordinariness of strong emotions is also evident in Maureen's turn-final tag question, 'is it' (line 6), which mobilizes support for an assertion made within the speaker's domain (Heritage, 2012), providing the children the opportunity to display their independent access to this emotional understanding through their own experience or general social knowledge. This works to position the children as collaborators in the knowledge and assessment being constructed as Maureen invites their participation, and Tristan's 'no' and headshake (line 7), confirm this is something he either knows already or can agree with.

Maureen continues with a further collective understanding, 'and sometimes we express them in ways that (.) we don't want t:.o (.) and that makes us feel silly' (lines 8-10). This presents the circular nature of emotions - we behave in certain ways because of strong feelings, which results in further emotions. For Sacks, 'we' is a reference that 'may refer to all members of a category that have ever lived and may ever live' (Sacks, 1992, p. 335), so Maureen again pushes back against any inference that the children are being singled out. Instead, Maureen's use of collective person references normalises, contextualises, and formulates this generalised pattern (Edwards, 1994). This continues in Maureen's upshot, '으. We nee:d to learn to control our feelings >don't we' (lines 12-13), that hints at 'control' as a solution to inappropriate emotional expression, which we all 'need'. While the turn-final tag, 'don't we', positions the children as participatory collaborators who share access to this solution.

\section{Normalising anger}

We have shown how understandings about emotions are co-produced as ordinary within the coaching sessions. This work forms a vital component of the steps taken to address the children's ability to recognise the emotions of themselves and others as both visible and 
normal. In this section we show how the generic 'everybody-ness' of emotions is recalibrated in a way that also opens up the specificity of emotional experiences in 'angry moments'. By bringing in the experiences of the individual children, the session moves on to co-construct a sense of what 'anger' is and where the boundaries of ordinary, valence-free anger lie. This forms part of a step-by-step progression towards the introduction of the 'self-talk thinking tool'.

While the collective proterms construct the universality of emotions and the tag questions highlight the shared understandings about them, as the session progresses Maureen begins to invoke specific emotions and the idea that it is individual experiences that are shared. This is evident in the following extract that follows a discussion after a vignette is shared to evoke feelings of anger for the children.

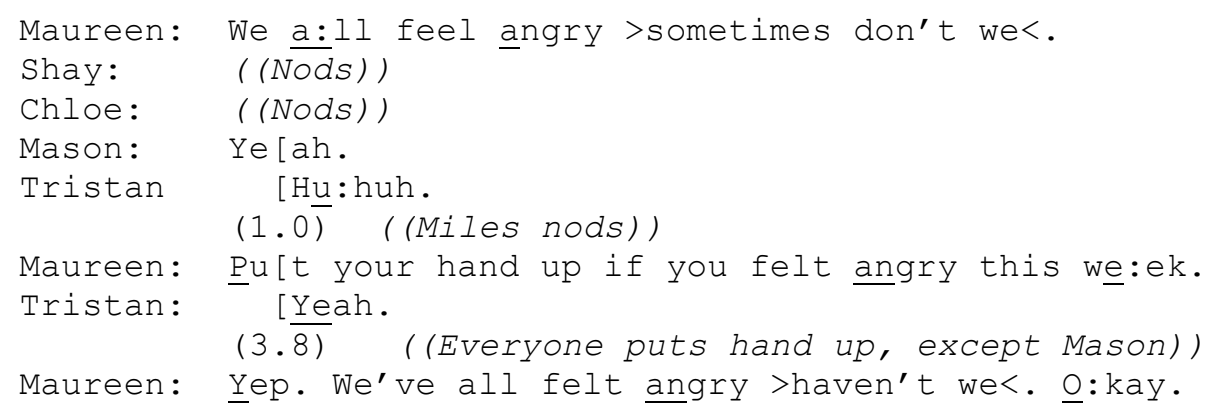

Maureen opens the discussion with the summative, 'We a:ll feel angry $>$ sometimes don't we $<$ ', using the by now familiar collective proterm 'we', the inclusive 'all', and the turn-final tag. These work together to position the children within the 'normal, standard or expected' category of people who 'sometimes' feel angry, establishing this as common knowledge (Edwards, 2007). At this point, Maureen begins to 'zero in' (Schegloff, 2000, p. 715) by inviting the children to raise their hands 'if you felt angry this we 
shift from the general and inclusive towards the specific, in terms of both individual experience and time frame. Schegloff's (2000) notion of 'granularity' is important within interaction because it is at this level of detail that people gain access to experiences.

Therefore, the turn is designed to do two things. First, the hand raising seems symbolic of being 'counted' in both senses of the word. Maureen's claim that 'we all feel angry sometimes' is reinforced as everyone (except Mason) raised their hand, which is visible to the children and reinforces the 'normalness' of anger. In this sense it defines the importance of the message being conveyed in line 1 and the normalising action being performed by it. Second, the turn brings into play the children's everyday reality. By asking them to locate and bring to mind an actual experience within their week the children can contextualise the feeling of anger in a meaningful way, and use their situated experience to make sense of the unfolding discussion. This sharing of individual experience to produce a collective understanding is ratified as Maureen acknowledges the raised hands reaffirming, 'Yep. We've all felt angry >haven't we $<$. O.:kay' (line 10). Having established the ordinariness of anger, Maureen invites the children to assess experiences of anger.

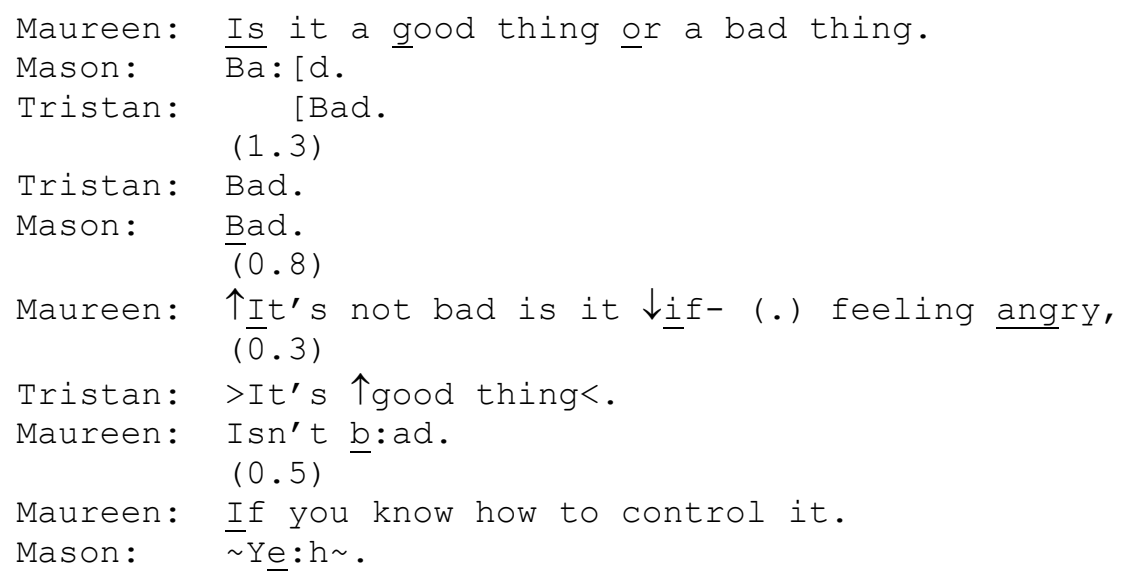


The fixed choice question requires that the children assess anger as either 'good' or 'bad'. Both Mason, and Tristan respond 'bad', but with her evaluative third-position turn Maureen challenges this (line 20). The assertion 'it's not bad' counters the boys' answer, but this corrective work is minimised by the tagged 'is it.' The tag implies that the children 'already know' anger isn't bad, despite their answers, and as such Maureen supports the children's participation. Tristan then asserts a new understanding, 'it's a good thing' (line 22), and Maureen repeats, 'isn't $\underline{b}$ :ad' (line 20), to reiterate her third turn evaluation. She then introduces a contingency or conditionality for this not-negative assessment of anger, 'If you know how to control it' (line 22). There is a logical inference to be made here; uncontrolled anger is bad. However, this is not made explicit as Maureen takes a more positive valence to leave this message inferable. The children's involvement in this sequence, starting in extract 3, shows how they have engaged as active participants in producing understandings about anger via a step-by-step progression, with increasing granularity and specificity.

In the extracts shown so far, the children's engagement in the discussion has been carefully scaffolded by Maureen in subtle but important ways. The collective person references are 'specifically vague' (Garfinkel, 1967, p. 41) in that they include anyone and everyone whilst they also directly specify the children. Throughout, the questions are designed not only to invite and support the engagement of the children, but also to construct them as knowing, thereby orienting to their expertise and authority over their own experiences and lifeworlds (Butler et al., 2010). One upshot of these techniques is that in addition to being treated as 'ordinary experts', either implicitly through turn-medial tag questions or explicitly through invitations to participate, the methods support interactional spaces where the children can initiate their own contributions to the discussion. This is evident in the following example, which continues directly on from the previous extract. 
(5)

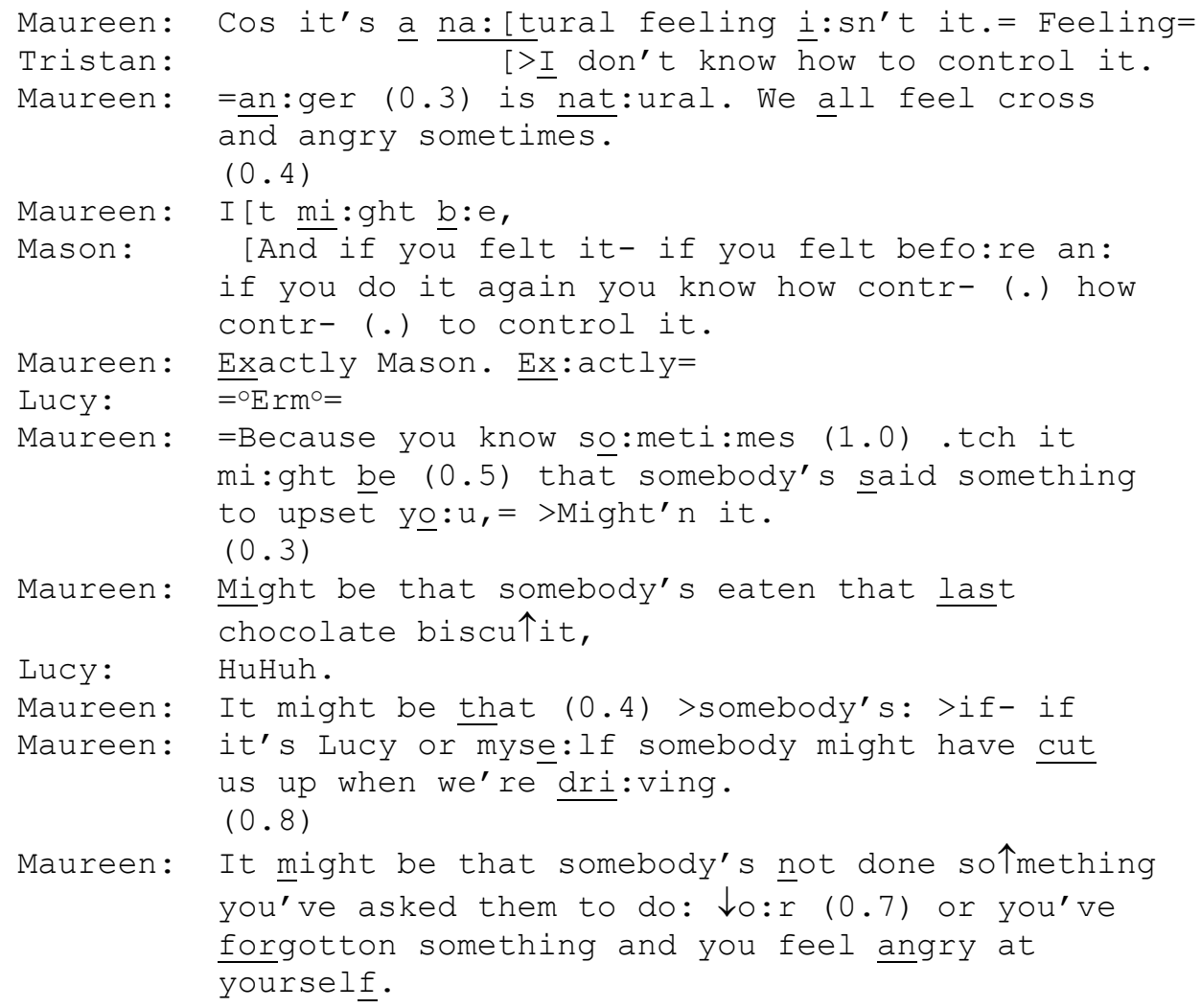

The extract begins with more of the normalising work (Edwards, 2000; 2007) that Maureen has been doing throughout, asserting the 'naturalness' of feeling 'cross and angry' (line 2728) as both inclusive ('we' and 'all') and known-in-common ('isn't it'). In overlap with this, Tristan responds to Maureen's earlier assertion (line 23, extract 4) reporting a subjective experience, 'I don't know how to control it', as if verbalising a realisation or acknowledgment in light of Maureen's talk. This turn is neither oriented to as a contribution to the on-going talk, or as an intrusion. This demonstrates how in these sessions, noninteractionally relevant contributions are both possible and unsanctioned, and allow for individual experiences to be heard, whilst a group-relevant focus is maintained.

Mason then initiates his contribution, 'And if you felt it- if you felt befo:re an' if you do it again you know how contr- (.) how contr- (.) to control it' (line 31-33). The prefacing 'and' 
connects his reasoning to Maureen's prior turn, thereby actively constructing common knowledge. Mason's use of generic person references ('you') is aligned with Maureen's use and constructs his contribution as being true for all, and as an ordinary understanding for recognising and controlling anger. He uses his social understanding and the 'collectivity's corpus of knowledge' (Sharrock, 1974, p. 45) to make sense of the experience by connecting what people know and what they do as a practice for managing anger. Maureen's high-grade assessment (Antaki, 2002) affirms Mason’s reasoning, ‘Exactly Mason. Ex:actly’ (line 37) and ratifies his expressed understanding.

In the same way that Mason connected his talk by using the preface 'and', Maureen uses 'because' to include Mason's contribution before continuing her abandoned turn from line 30, 'Because you know sọ:meti:mes (1.0) . tch it mi:ght be (0.5) that somebody’s said something to upset yo: $\mathrm{u},=>$ Might' $\mathrm{n}$ it' (lines 36-38). She continues to list hypothetical things that 'might' make 'somebody' angry, descriptively working anger up as being directed at ordinary everyday things, therefore rational and spontaneous rather than dispositional and irrational (Edwards, 1997), to continue the 'unpathologising' work seen throughout.

\section{Using metaphors to construct experiential aspects of anger}

As the session progresses, Maureen increases the focus on the children's individual experiences. Although the generic ordinariness of emotions, and anger in particular, is a vital part of redressing the 'pathologisation' of ADHD behaviours, there is a need to return to the children's own individual experiences of anger which is problematic at times. She begins to 
address this in the following extract as she introduces the metaphor of anger as a volcano with the potential to erupt (see Lakoff (1987) on emotion metaphors).

(6)

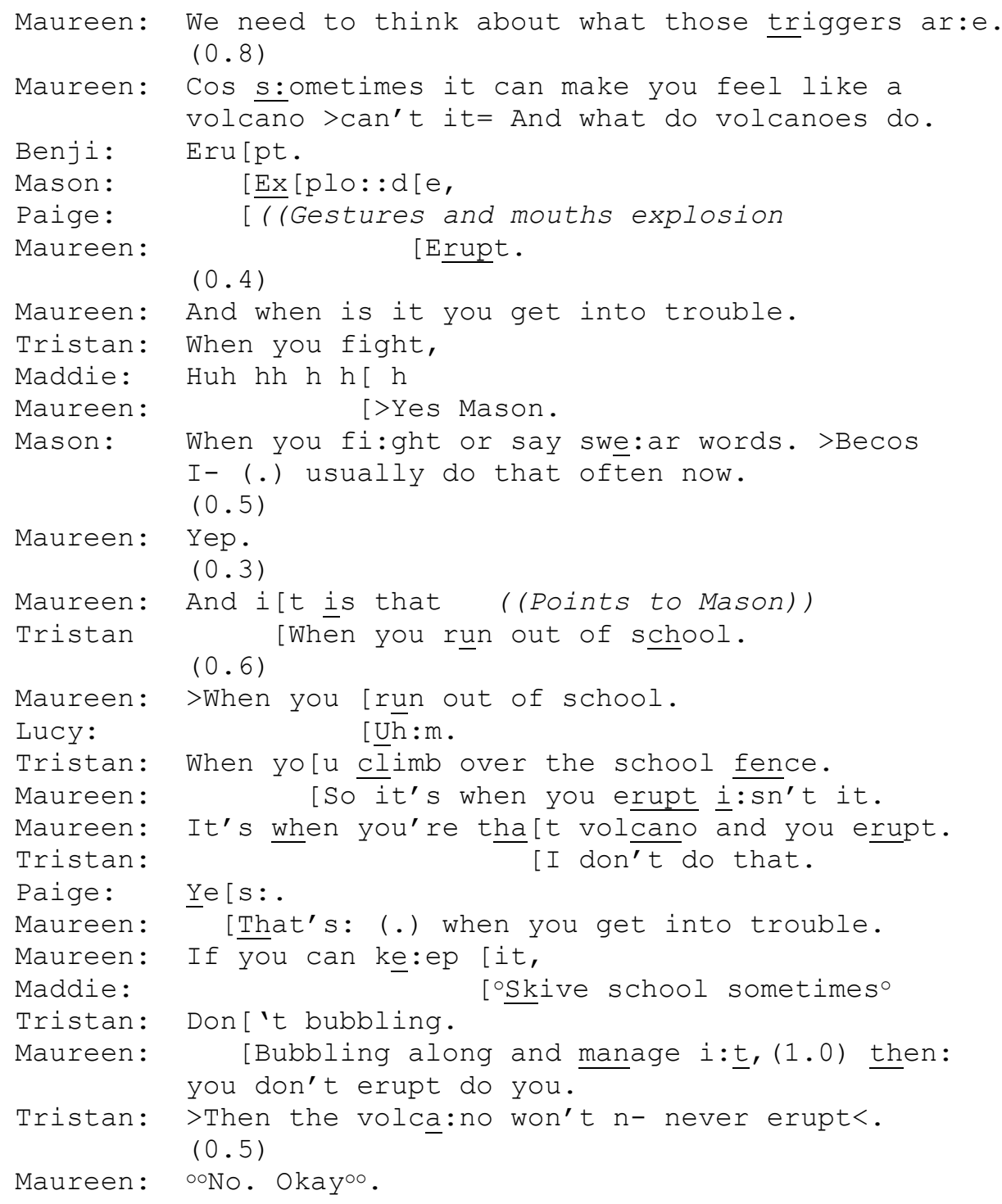

Metaphors are a conceptual resource used to construct a narrative description of emotional expressions in real life. Metaphors of anger as bubbling or boiling are ways to construct anger as passive and experiential (Edwards, 1997). Examples of 'erupting emotions' are shared in this sequence as part of a shift from the more general and hypothetical to the children's own experiences, which is managed in part by Maureen's referential shift from 'we' to 'you', in a 
narrowing of recipiency. The children provide a selection of appropriate actions (lines 5-8) in response to Maureen's question about what volcanoes do. They then contribute examples of when they 'get into trouble' by offering, 'when you fight' (line 11), 'say swe.ar words' (line 14), 'run out of school' (line 20), or 'climb over the school fence' (line 24).

Interestingly, in proffering these examples Tristan and Mason both use the generic 'you' to talk about what seem to be descriptions of personal experiences. This is a nice illustration of how the work of the session can help the children recognise their own experiences as ordinary, to unpathologise behaviours potentially seen as being bound to ADHD. Mason then shifts to the subjective 'I' to speak about his own experiences through his admission that he fights and says swear words when he is angry (lines 14-15). This disclosure seems to allude once more to the context in which this interaction takes place and the reasons why the children are attending.

Throughout, Maureen acknowledges and validates the children's experiences, then closes the 'sharing' by formulating these specific examples as 'eruptions' (lines 25-29). By using the volcano metaphor to contextualise anger's physical feeling, Maureen makes available another practical tool and ordinary method for the children to use, to recognise and manage their anger. The solution is, 'if you can ke:ep it bubbling along and manage it then you don't erupt' (line 30-34). Tristan formulates the upshot, '>Then the volca:no won't n- never erupt $<$ ' (line 35) prefacing 'then' to connect his talk to Maureen's in a collaborative building and discovery of knowledge and understanding. Tristan's use of 'the', and Maureen's use of 'it', construct the volcano as a separate entity that sits within the children, but is not part of them. By separating the volcano from the person, an interesting psychological interpretation can be 
considered; the children are in charge of 'the' volcano and as such they can control it if they use the tools being taught to recognise their anger and externalise it in this way.

The extract comes at the end of a long stretch of talk that began in extract 3 when Maureen made it known to the children that 'we all feel angry sometimes'. The discussion progressed to challenge the belief that anger 'is not a bad thing' in extract 4, before moving to normalise anger and assert the need for control in extract 5 . The talk ended in extract 6 above, when anger was described as a volcano, offering the children a practical tool for recognising and controlling their anger. The extended analysis of these extracts has shown how the children's knowledge and assessment of anger has been shaped and developed through a step-by stepprogression, collaboratively constructed to provide a practical understanding and tools for the children to use to help them recognise and control their anger in the future. This collective, practical understanding is both generic and specific and serves as a basis for introducing a classic cognitive-behavioural method: self-talk.

\section{Self- talk thinking tool}

For Goffman (1978), self-talk is a ritualized behaviour, one that we practice for different reasons. Maureen is teaching this ordinary practice as a formalised method for controlling anger. In introducing self-talk into the children's toolkit, there is a marked shift in the participation structure, as Maureen positions herself and Lucy as instructors. In the moments leading up to the extract the group have enacted, or watched, a role-play scenario in which one member of the group has acted being angry and another member has reacted to calm her down. The role-play was used to start a discussion that involved describing physical displays of anger in other people. 
(7)

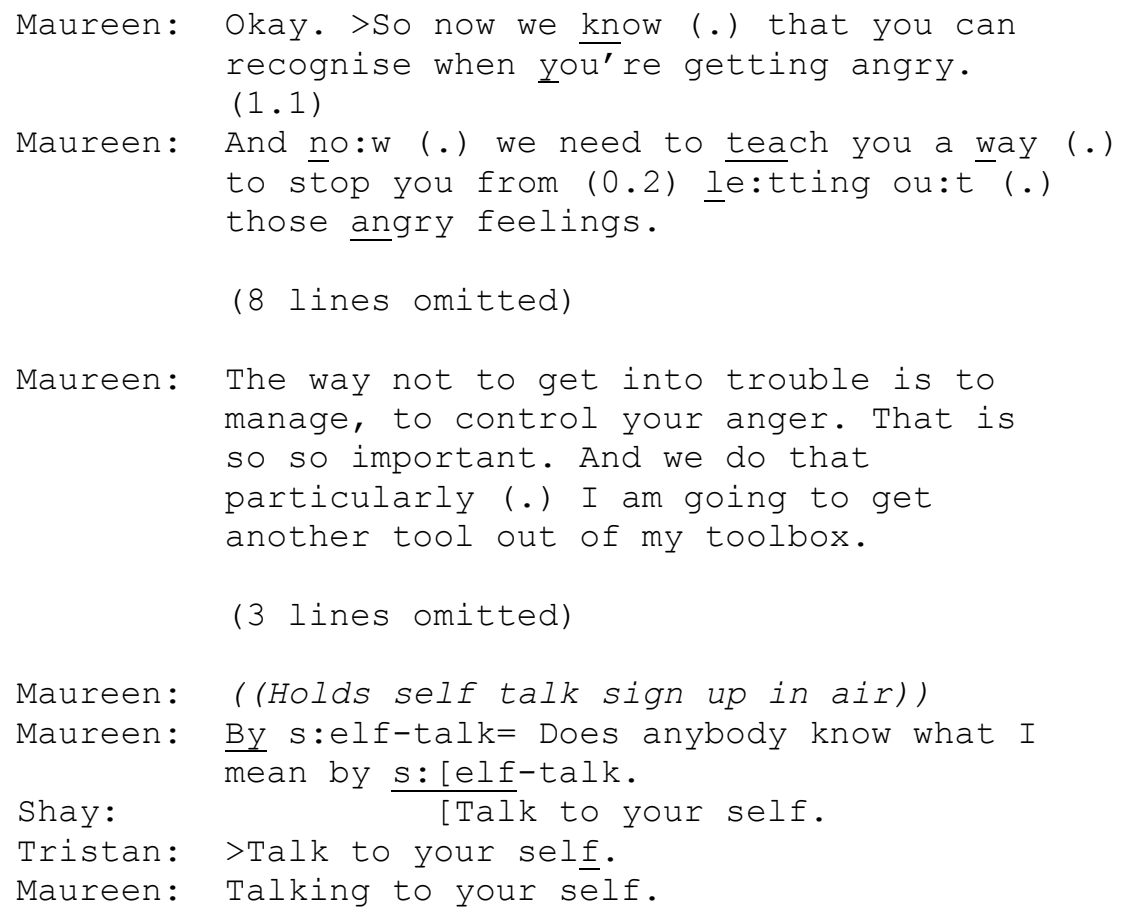

Maureen's summative turn (lines 1-2) assumes and attributes the children's competency in recognising 'when you're getting angry', on the basis that in their prior discussion the children did describe physical displays of anger. Maureen then introduces the self-talk tool as something that 'we need to teach you ... to stop you from letting out those angry feelings' (lines 4-6). Unlike previous instances, the all-inclusive 'we' refers only to Maureen and Lucy, as coach and assistant. This then begins to partition the group into a two-party organisation: the children and the instructors (Butler, 2008; Sacks, 1992). As such, there is a shift in the distribution of the rights, obligations, and expertise amongst the group. In lines 1-6, Maureen switches the tense from speaking in the present to the future, which lends itself to an instructional or advisory mode. The future-oriented footing in 'when you're getting' (line 2) and 'letting out' (line 5) evoke a time when the children will get angry and express that anger, and highlights the shift from the earlier normalising work to the 'main business' of providing the children a specific anger management tool. 
We also see a partitioning in terms of the ownership of angry emotions. Maureen's descriptions, 'those angry feelings' (line 6), separate the emotion from the children, similar to the distancing work seen in extract 6 . Anger is formulated as something 'other than' the individual; helpfully separating the person from the emotion to resist the idea that anger is dispositional (Edwards, 1997) and part of the children's identity. Having introduced 'selftalk' from her 'tool box' (line 14) Maureen invites the children to identify if they know what 'self-talk' means (lines 19-20). The children's responses are affirmed as correct, and this then signals the introduction of self-talk phrases.

In data not shown, the children are invited to come up with things they could say to themselves to 'calm down'. Two phrases are nominated: 'tell yourself to calm down' and 'tell yourself not to get angry'. Using the generic person reference 'yourself' the children formulate these bits of self-talk as instructions to one-self, rather than talk to one-self. In the following sequence Maureen builds on their contributions to turn generic instructions into personalised self-talk.

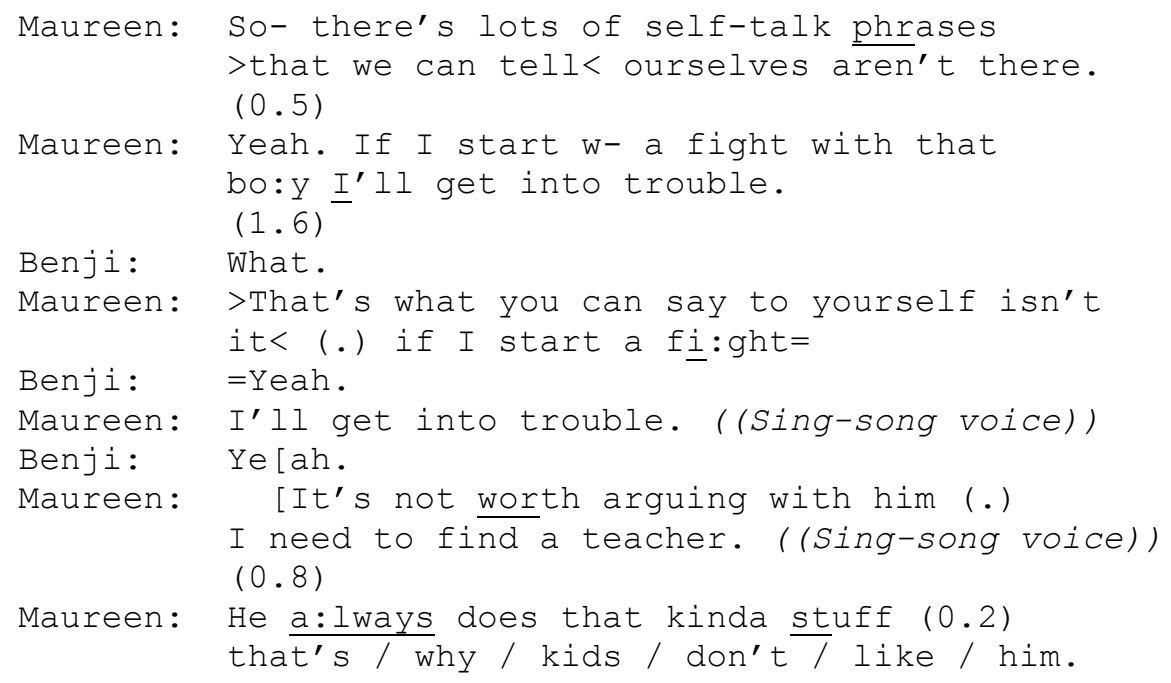




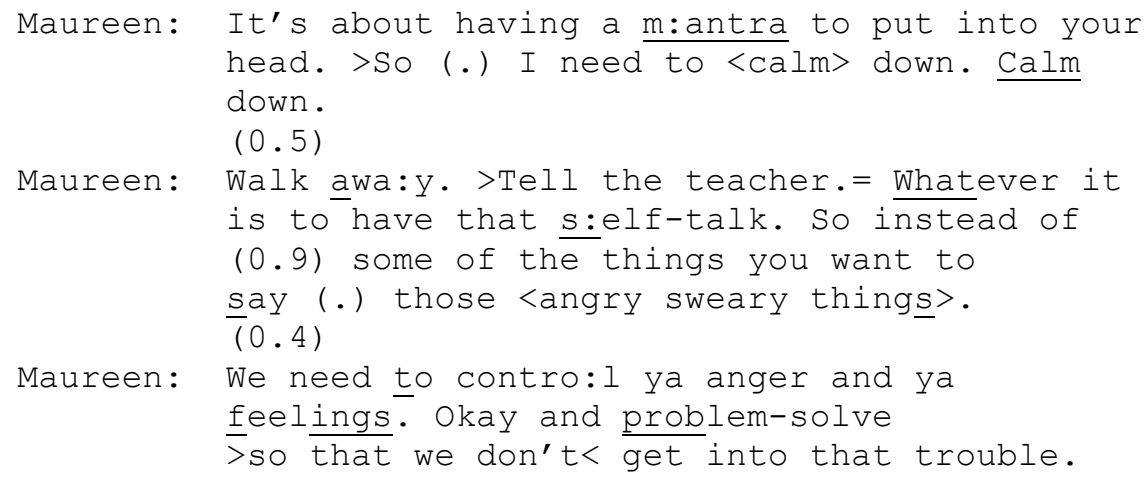

Maureen begins this sequence with a return to the inclusive 'we' that flattens out the relationship between her, Lucy, and the children. The self-talk phrases are 'anyone's' and the children are positioned as equally able to recognise the truth in the statement as shown with the tag. Maureen then offers a list of hypothetical phrases (lines 4-5) designed as 'script proposals' (see Emmison et al., 2011), using direct reported speech to give the children access to what they could say in such situations. Maureen adopts the 'animator' role (Goffman, 1981) as if speaking on behalf of the children as authors of the self-talk. She widens the children's collective 'corpus of knowledge' (Sharrock, 1974) to the many possible ways of formulating such talk for themselves in practice: 'I need to find a teacher', 'I need to calm down'.

Stepping outside of the animator role briefly, Maureen explains it is about having a 'mantra to put into your head' (line 18). This explanation is a nice illustration of how the practical method (saying something to yourself) is treated as a cognitive practice. Putting a phrase into one's head makes it transportable and available to be drawn on in multiple situations. What is being done here could be described as the explicit seeding of a script formulation (Edwards, 1997) that can be made interactionally relevant and used in everyday situations. In closing this sequence, Maureen formulates, 'that self-talk' (line 23), as a tool that the children can use to replace 'those angry sweary things' (line 25), 'to control ya anger and ya feelings' (lines 
27-28), 'and problem solve $>$ so that we don' $t<$ get into that trouble' (line 28-29). Maureen returns to the inclusive collective 'we' (line 27 and 29) to speak about self-talk as an ordinary practice that can be used by everyone to control anger and not get into trouble. This return to the ordinary is now done on the basis that a jointly produced understanding of self-talk has been formalised and scripted to be reflective of the children's everyday reality, but constructed as an 'ordinary' practice that is used by everyone to manage anger. This continues the normalising work seen throughout to prevent the children from being singled out and dispositionally defined by their emotions and behaviours.

\section{Summary}

This chapter has tracked the delivery of a small element of a cognitive-behavioural program for children with a diagnosis of ADHD. The aim has been to highlight how much work is done not just through the content of the program and the tools that are introduced to the children, but in the ordinary interactional practices through which the program is delivered. The skill of the coach does not rest so much in her use of cognitive-behavioural methods, but in the specifics of how the material is packaged, organised, and delivered. These details are reliant on interactional communicative skills that are regularly 'seen but unnoticed' (Garfinkel, 1964). Simple methods with immense power in constructing ADHD, its behaviours, emotional consequences, and the identities of children diagnosed with it.

Through the implementation of cognitive-behavioural methods such as metaphors, tone of voice, and self-talk the sessions have focused on the behavioural, emotional, and social difficulties associated with a diagnosis of ADHD. The future oriented focus of the coaching made the tools and strategies available to be drawn on and used by the children in real life 
challenges within their everyday world. The analysis has identified how the teaching of emotional knowledge was co-produced between the coach and the children through the use of the IRE and tag questions; the ordinariness of emotional states was achieved through the use of person references, and both were fundamental to the delivery of the program and the teaching of tools.

Knowledge and understanding was developed over a step-by-step sequence that invited increasing participation from the children and ultimately established understandings as shared. The IRE was used as part of this work to elicit understanding and to continually check and ensure that joint understanding was achieved (Edwards \& Mercer, 1987). A further way this was done was via tag questions that invited displays of understanding by the children. Mid-turn tags were used to treat some bit of talk as already known by the children, or as something they could accept and agree with as part of the knowledge building process, and to mark the importance or significance of an assertion. Slots for affirmation were not always left for the children and as such Maureen assumed and attributed understanding. While turn-final tags invited agreement from the children, they also marked the talk as a kind of judgment or conclusion.

The practices used throughout effectively orient to the ordinariness of the children's experiences and behaviour. This was primarily done through the seemingly minor practice of using generic and inclusive person references. The collective person references used to normalise emotions seem to preclude (extracts 1-5) and lead up to a shift from the collective to the subjective (extract 6-8), to speak about the children's own emotional experiences and enable instruction, before shifting back at the end of extract 8 to speak once more in ordinary terms about self-talk as a practice available to all. Thus, the rather technical and theoretically 
driven notion of self-talk is sequentially packaged up and produced as an ordinary practice. More specifically, the 'unpathologising' of the children's behavior was achieved through separating anger (extract 6 and 7) from the children, so this emotion did not become dispositional and bound to their identity as an 'extraordinary' description that could be used to categorise them. This 'unpathologising' is important given that previous research has rarely addressed the impact of ADHD emotions and behaviours on self-esteem and selfconcept. Despite there being research that highlights how children tend to define themselves by their ADHD behaviours (Krueger \& Kendall, 2001), and that experiences of ADHD often impact negatively on their self-esteem (Travell \& Visser, 2006), studies have not focused on the ways in which children can be supported to counteract negative effects, but this has been a focus for this chapter.

\section{Clinical relevance}

The RAPID program has been found to be effective in helping children diagnosed with ADHD gain knowledge and skills to improve interpersonal relationships (Young, 2013). However, we believe that the therapeutic benefits of this program are not merely the result of the cognitive-behavioural theories and principles being applied through the RAPID program, but also the less noticed and less understood interactional practices through which the program is delivered. In this chapter, we have outlined how 'ways of speaking' in the delivery of the program, which are often treated as implicit, common sense, or intuitive, have constructed a more positive version of $\mathrm{ADHD}$, this in turn has implications for real life constructions of ADHD identities and associated understandings. 
There is vital clinical relevance to be found in the specific methods and practices used in the actual delivery of this program, and others like it. An interactional analysis has revealed the ways in which Maureen delivers the RAPID program, (1) to treat the children as experts about ADHD and their experiences of it, as their participation and agency is a vital part of the program; (2) to introduce cognitive tools in a meaningful way that is inclusive of the children's knowledge and experiences; and (3) to normalise emotions and prevent excessive emotional expression from becoming a defining part of their identity. These findings bridge the gap between theory and practice because identification of the methods actually used in delivering the cognitive-behavioural program, make these same methods available for practitioners and professionals to recognise and apply to their own practice.

\section{Clinical practice highlights}

1. The asymmetrical relationship between coach or therapist and children can be minimised via questioning practices (tag questions position the children as already having knowledge) to invoke and promote the expertise and agency of the children.

2. The step-by-step introduction of cognitive-behavioural tools can be introduced through the collaborative production of shared knowledge and experience.

3. Normalising practices, such as collective and inclusive person references ('we'), can be used effectively to 'unpathologise' emotions, behaviours and experiences that may otherwise be especially salient for children with a diagnosis of ADHD, which can help address issues of self-concept and identity.

\section{References}

Antaki, C. (2002). "Lovely": Turn-initial high grade assessments in telephone closings.

Discourse Studies, 4 (1), 5-23.

Barkley, R. (2006). Attention-deficit hyperactivity disorder: A handbook for diagnosis and

Treatment $3^{\text {rd }}$ Edition. New York: Guildford Press. 
Bradley, L., \& Butler, C.W. (forthcoming). 'People with ADHD...: An interactional analysis of an ADHD support group.

Brady, G. (2014). Children and ADHD: Seeking control within the constraints of diagnosis. Children \& Society, 28, 218-230.

Burridge, J.D. (2008) "“Hunting is not just for bloodthirsty toffs": The Countryside Alliance and the visual rhetoric of a poster campaign'. Text and Talk, 28 (1), 31-53.

Butler, C.W. (2008). Talk and Social Interaction in the Playground. Aldershot: Ashgate.

Butler, C.W., Potter, J., Danby, S., Emmison, M., \& Hepburn, A. (2010). Advice-implicative interrogatives: Building “client-centred” support in a children's helpline. Social Psychology Quarterly, 57, 265-289.

Danforth, S., \& Navarro, V. (2001). Hyper talk: Sampling the social construction of ADHD in everyday language. Anthropology \& Education Quarterly, 32 (2), 167-190.

Edwards, D. (2000). Extreme case formulations: Softeners, investment, and doing nonliteral. Research on Language and Social Interaction, 33 (4), 347-373.

Edwards, D. (2007). Managing subjectivity in talk. In A. Hepburn \& S. Wiggins (Eds.), Discursive research in practice: New approach to psychology and interaction. Cambridge, Cambridge University Press: pp. 31-50.

Edwards, D. (1994). Script formulations: An analysis of event descriptions in conversation. Journal of Language and Social Psychology, 13, 211-247.

Edwards, D. (1997). Discourse and cognition. London: Sage.

Edwards, D., \& Mercer, N. (1987). Common knowledge: The development of understanding in the classroom. London: Methuen.

Emmison, M., Butler, C.W., \& Danby, S. (2011). Script proposals: A device for empowering clients in counselling. Discourse Studies, 13 (3), 3-26. 
Garfinkel, H. (1964). Studies in the routine grounds of everyday activities. Social Problems, $11(3), 225-250$

Garfinkel, H. (1967). Studies in ethnomethodology. Englewood Cliffs: Prentice-Hall.

Gavita, O., \& Joyce, M. (2008). A review of the effectiveness of group cognitively enhanced behavioural based parent programs designed for reducing disruptive behaviour in children. Journal of Cognitive and Behavioural Psychotherapies, 8 (2), 185-199.

Goffman, E. (1978). Response cries. Language, 54 (4), 787-815.

Goffman, E. (1981). Forms of talk. Oxford: Oxford University Press.

Horton-Salway, M. (2011). Repertoires of ADHD in newspaper media. Health, 15 (5), $533-$ 549.

Hepburn, A. \& Potter, J. (2010). Interrogating tears: Some uses of 'tag questions' in a child protection helpline. In A.F. Freed \& S. Ehrlich (Eds). "Why Do You Ask?”: The Function of Questions in Institutional Discourse (pp. 69-86). Oxford: Oxford University Press.

Heritage, J. (2012) Epistemics in Conversation. In J. Sidnell \& T Stivers (Eds.), The Handbook of Conversation Analysis. John Wiley \& Sons, Ltd, Chichester, UK: pp. 129.

Houck, G., Kendall, J., Muller, A., Morrell, P., \& Wiebe, G. (2011). Self-concept in children and adolescents with Attention Deficit Hyperactivity Disorder. Journal of Pediatric Nursing, 26 (3), 239-247.

Krueger, M., \& Kendall, J. (2001). Descriptions of self: An exploratory study of adolescents with ADHD. Journal of Child and Adolescent Psychiatric Nursing, 14 (2), 61-72.

Lakoff, G. (1987). Women, fire and dangerous things: What categories reveal about the mind. Chicago: University of Chicago Press.

Lawrence, S.G. (1996). Normalizing stigmatized practices: Achieving co-membership by 
"Doing being ordinary". Research on Language and Social Interaction, 29 (3), 181 218.

Margutti , P., \& Drew, P. (forthcoming). Positive evaluations of student answers in classroom instruction. Language and Education.

Mehan, H. (1979). 'What time is it, Denise?”:Asking known information questions in classroom discourse. Theory into Practice, 18 (4), 285-294.

Polanczyk, G., de Lima, M., Horta, B., Biederman, J., \& Rohde, L. (2007). The worldwide prevalence of ADHD: a systematic review and metaregression analysis. American journal of psychiatry, 164(6), 942-948.

Ryan, N., \& McDougall, T. (2009). Nursing children and young people with ADHD. Oxon: Routledge.

Sacks, H. (1984b). “On doing 'being ordinary””. In J. M. Atkinson and J. Heritage (Eds.), Structures of social action. Cambridge: Cambridge University Press: pp. 413-429.

Sacks, H. (1995). Lectures on conversation (Vol 1. G. Jefferson, Eds.) Padstow, T.J. Press Ltd.

Schegloff, E. A. (2007). “On granularity”. Annual Review of Sociology, 26, 715-720.

Schegloff, E. A. (2007). Sequence organization interaction. Cambridge: Cambridge University Press.

Sharrock, W. W (1974) On Owning Knowledge. In R.Turner (ed.), Ethnomethodology. Harmondsworth, Penguin: pp. 45-53.

Sneijder, P., \& te Molder, H. (2009). Normalizing ideological food choice and eating practices. Identity work in online discussions on veganism. Appetite, 52, 621-630.

Travell, C., \& Visser, J. (2006). 'ADHD does bad stuff to you': Young peoples' and parents' experiences and perceptions of Attention Deficit Hyperactivity Disorder (ADHD). Emotional and Behavioural Difficulties, 11 (3), 205-216. 
Young, S. (2009). RAPID: Reasoning and problem solving for inattentive detectives. London, England: Psychology Services Limited.

Young, S. (2013). The "RAPID” Cognitive-behavioural therapy program for inattentive children: Preliminary findings. Journal of Attention Disorders, 17 (6), 519-526.

Wehmeier, P. M., Schacht, A., and Barkley, R. A. (2010), Social and emotional impairment in children and adolescents with ADHD and the impact on quality of life, Journal of Adolescent Health, 46(3): 209-217.

\section{Recommended reading}

Mehan, H. (1979). 'What time is it, Denise?”: Asking known information questions in classroom discourse. Theory into Practice, 18 (4), 285-294.

Sacks, H. (1984b). “On doing ‘being ordinary””. In J. M. Atkinson and J. Heritage (Eds.), Structures of social action. Cambridge: Cambridge University Press: pp. 413-429.
Abbreviations:
ADHD - Attention Deficit Hyperactivity Disorder.
RAPID - Reasoning and Problem Solving for Inattentive Detectives. 